\title{
VAPOR PIRAPAMA: UMA PERSPECTIVA MUSEOLÓGICA
}

laly Cintra Ferreira*

Jhonatta Jeremias dos Santos Silva*

Ezequiel Sena do Nascimento**

Carlos Rios***
RESUMO: O presente artigo objetiva o desenvolvimento de um circuito arqueoturístico do Vapor Pirapama, utilizando uma metodologia de curadoria museológica que ressalte os vieses turístico, histórico, arqueológico e cultural, com ênfase em alguns aspectos da Arte Naval do naufrágio. Os procedimentos metodológicos envolvidos são: pesquisas bibliográficas, de materiais e imagéticas pertinentes ao assunto. Existem grandes possibilidades de êxito na adoção desse sistema pelo setor turístico, sem que este deixe de cumprir seu papel voltado para o entretenimento e ainda agregue valor ao patrimônio cultural subaquático da cidade do Recife.

Palavras-chave: Arqueologia Subaquática. Museologia. Turismo Subaquático. Vapor Pirapama.

ABSTRACT: This article aims to develop an archaeotourism circuit of the Vapor Pirapama, using a methodology of museum curation that emphasizes the tourist, historical, archaeological and cultural biases, with emphasis on some aspects of Naval Art of shipwreck. The methodological procedures involved are: bibliographical research, materials and images pertinent to the subject. There are great possibilities for success in the adoption of this system by the tourism sector, without ceasing to fulfill its role for entertainment and still add value to the underwater cultural heritage of the city of Recife.

Keywords: Underwater Archeology. Museology. Underwater

\footnotetext{
*Arqueólogos formados pela Universidade Federal de Pernambuco - UFPE

**Aluno do curso de Arqueologia da Universidade Federal de Pernambuco - UFPE

***Docente do Departamento de Arqueologia da Universidade Federal de Pernambuco - UFPE
} 


\section{Introdução}

Entre a comunidade dos mergulhadores tornou-se unanimidade: Recife é considerada, pela mídia nacional, como a capital brasileira do mergulho em naufrágio. Dos anos de 1990 até a atualidade, já foram acrescentados mais de 20 pontos de mergulho com navios/embarcações naufragadas (acidental ou propositalmente) tanto no entorno dos portos de Recife e Suape (Figuras 1e 2) quanto em outras áreas de sua plataforma continental.

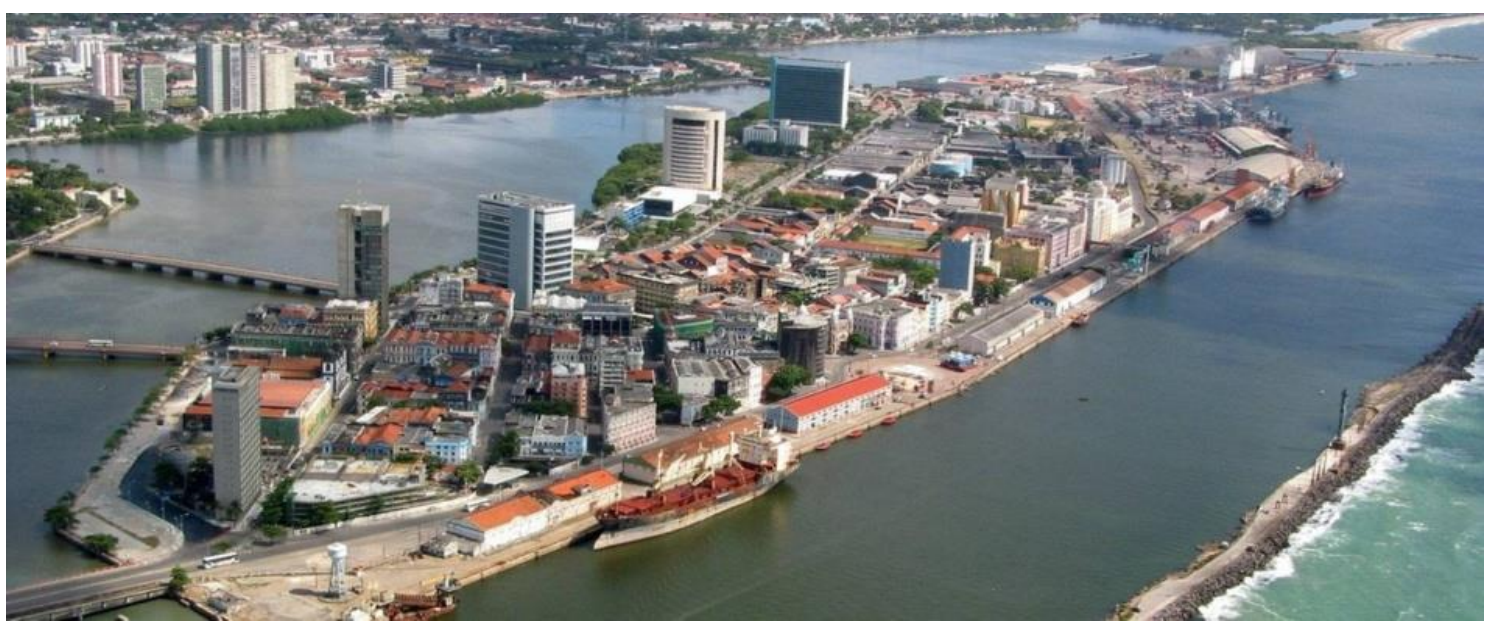

Figura 1: Vista aérea do Porto do Recife. Fonte: O Globo, 2016.

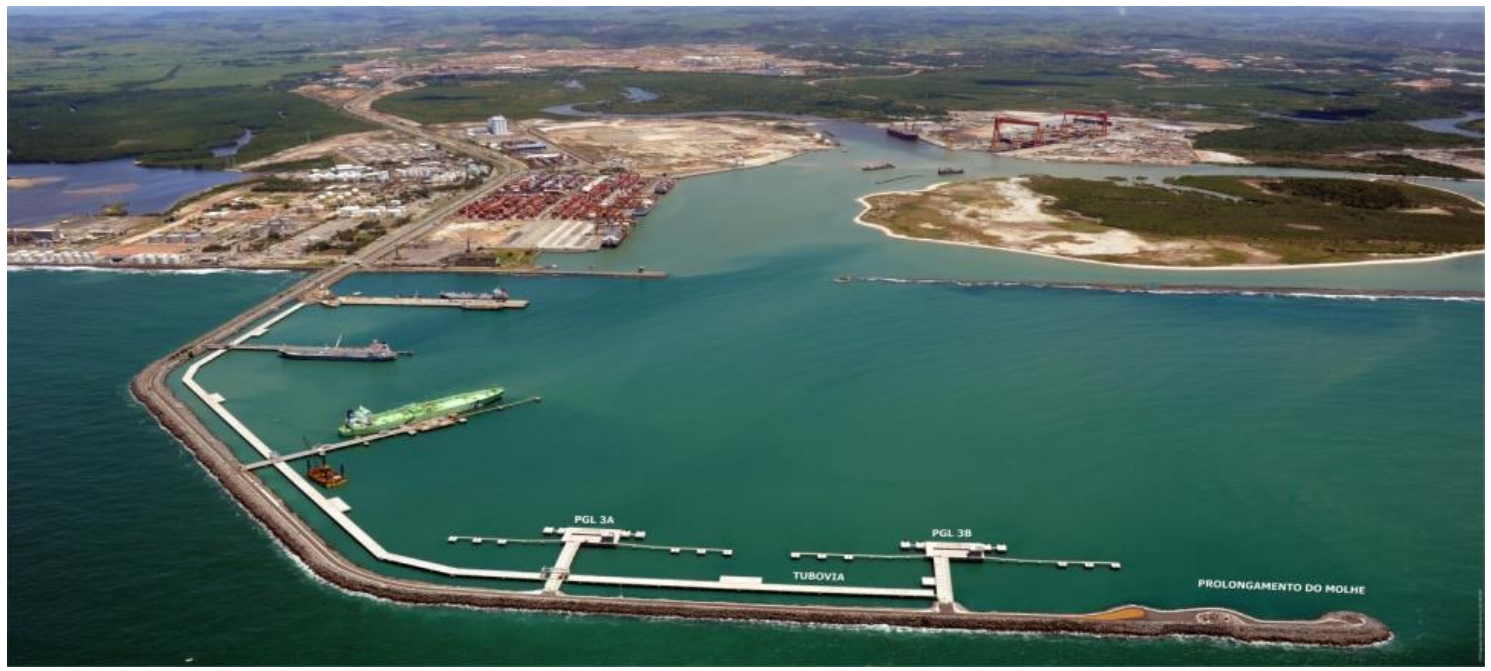

Figura 2: Vista aérea do Porto de Suape. Fonte: Suape Imprensa, acesso em set. 2016.

Apesar de a cidade do Recife oferecer essa diversidade de naufrágios, detentora de uma cronologia que vai desde o século XVII até o XXI, os mergulhos são, basicamente, voltados para a beleza das espécies vegetais e animais que habitam tais "recifes artificiais submersos", além de contar com outro atrativo que é a transparência da água em torno de $20 \mathrm{~m}$ e sua temperatura variando entre $25^{\circ} \mathrm{C}$ e $28^{\circ} \mathrm{C}$ (Rios, 2010). No entanto, não há o interesse em apresentar a história, os aparelhos e acessórios desses artefatos criados pelo homem. 
Desse modo, aproveitando essa lacuna inexplorada pelas operadoras de mergulho, o objeto de estudo é o Vapor Pirapama, conhecido nacional e internacionalmente, cujo passado conta com uma rica história antes de ter ido parar no fundo do mar de forma proposital. É com o intuito de que mais pessoas venham conhecer esse símbolo do patrimônio arqueológico subaquático de Pernambuco que esse artigo visa proporcionar uma experiência única, com a adoção do circuito arqueoturístico ao naufrágio do Pirapama, propondo transformá-lo em um museu em mar aberto.

\section{Vapor Pirapama}

O Vapor Pirapama possui uma história permeada por mitos que já se fundiram como verdade no imaginário popular. Sabe-se que ele

foi adquirido na Inglaterra pela Companhia Pernambucana de Navegação Costeira por Vapor (CPNCV), possuía casco de ferro, passando a operar em 04.06.1867. Tinha $60 \mathrm{~m}$ de comprimento, 10 de boca e 2,64 de calado, deslocando 312 toneladas. Suas máquinas possuíam 120 cavalos-vapor e era equipado com 34 tripulantes (Carvalho; Rios, 2011).

Um dos pontos altos de sua história com a navegação causa controvérsias até os dias atuais: o abalroamento com o Vapor Bahia, onde:

o levantamento documental sobre o evento indicou que os navios vinham em rumos contrários e coincidentes, o Pirapama partiu do Porto do Recife - PE, com destino aos portos do norte e o Bahia partiu do Porto de Cabedelo - PB, com destino aos portos do sul. Após o abalroamento o Pirapama retornou para o porto do Recife, de onde havia partido, com avarias e o Bahia afundou em poucos minutos (Barbosa, 2014:10).

O Pirapama permaneceu em reparos por 6 meses, devido aos danos sofridos com 0 abalroamento.

A partir daí a história que se seguiu é que o Pirapama sofreu reparos até setembro daquele ano na carreira do Arsenal de Marinha e voltou a navegar até 1890, quando se tornou um pontão para armazenamento de carvão no porto do Recife e foi afundado, propositalmente, pelo menos, dez anos depois (Rios apud Barbosa, 2014:49).

Considerado um dos dez naufrágios mais conhecidos do Brasil, o Pirapama é um dos pontos de mergulho mais próximo do porto do Recife ficando a 6 milhas náuticas $(11,112 \mathrm{~km})$ da costa, localizado a $08^{\circ} 03.364^{\prime} \mathrm{S} / 034^{\circ} 46.992^{\prime} \mathrm{W}$, em uma profundidade que varia de $19 \mathrm{~m}$ a $23 \mathrm{~m}$ (Sinau, 2014). 


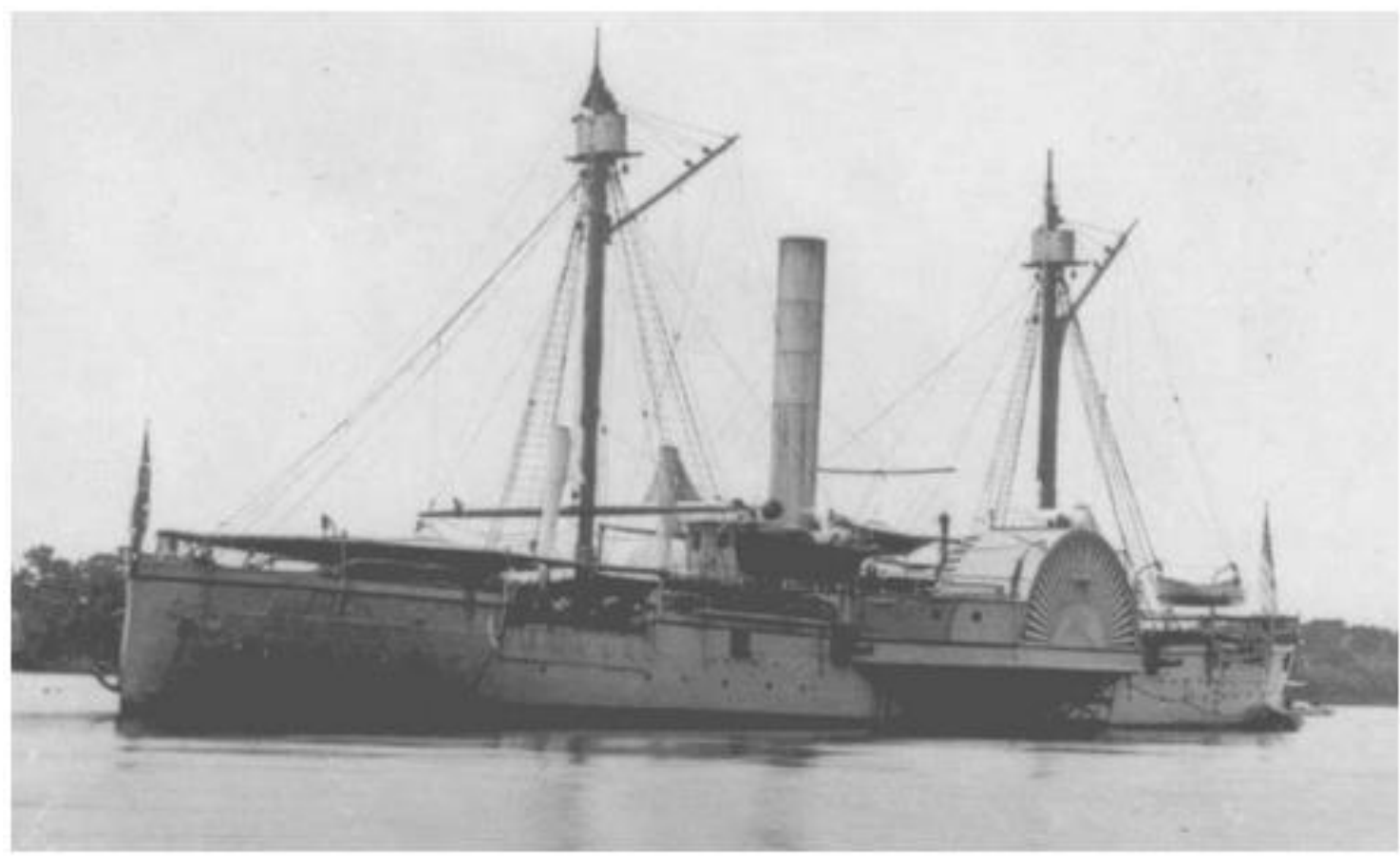

Figura 3: Vapor Pirapama, 1887. Fonte: Maurício Carvalho, acesso em ago. 2016.

\section{Propostas}

O fio condutor deste artigo está pautado na construção de um circuito museológico do Vapor Pirapama, com vieses turístico, histórico, arqueológico e cultural, com ênfase em aspectos da Arte Naval. O segmento turístico seria alcançado por meio de propaganda na mídia local, pela internet e por meio de folders deixados no Aeroporto Internacional do Recife/GuararapesGilberto Freire, em Centros de Atendimento ao Turista da Prefeitura do Recife espalhados pelo grande Recife e rede hoteleira. A parte histórica vai agregar valor ao trabalho por meio de pesquisa bibliográfica de fontes primárias e secundárias sobre: o nome Pirapama, a quantidade de navios que receberam esse nome, a empresa de navegação que o comprou, os dados planimétricos, especificações etc.

O arqueológico vai explorar os dados já trabalhados sobre o navio, mas nesse caso específico sob a ótica da arqueologia subaquática, buscando explicações científicas para a elucidação de questionamentos afetos ao navio.

O cultural engloba um novo olhar sobre o objeto de estudo que deixa de ser apenas um naufrágio com uma bela vida animal e vegetal para se tornar um vetor de conhecimento da Arte Naval, explicando cada parte daquele bem patrimonial descriminando a história, o uso e a função de cada artefato.

Esse novo olhar se materializa por meio de palestras específicas antes do embarque para o mar em sala de aula ou a bordo da embarcação de mergulho, onde os mergulhadores vão aprender sobre aquele naufrágio nos diversos segmentos propostos. 
Isto feito, em se chegando ao local do mergulho, como auxílio de instrutor treinado, o grupo irá conhecer o naufrágio com essa nova bagagem de informações, dando um novo sentido para o turismo de aventura que, neste caso, terá o aspecto cultural de um verdadeiro museu a céu aberto com placas informativas e visita guiada.

A confecção das placas é uma etapa importante e merece observações especiais. Estas conterão as informações históricas e técnicas sobre o Vapor Pirapama devem estar bem localizadas para uma boa visualização e junto ao naufrágio.

Não é indicado que as placas sejam diretamente fixadas sob ou sobre a superfície da embarcação. Essa medida provocaria avarias no vapor, que já está bastante fragilizado. Outro ponto a ser ressaltado é que nenhuma alteração deve ser feita no naufrágio, por ele também ser um objeto arqueológico (Goulart, 2014).

No que concerne ao material para a fabricação das placas, o acrílico mostrou ser o mais indicado. Por ser um material resistente, flexível, transparente, de pouco peso e fácil impressão. Entre outras atribuições, tem alta durabilidade, em torno de 10 anos, resistindo bem as intempéries do tempo.

As placas seriam fixadas em uma base de concreto (poita), próximas ao navio e seguindo a ordem do trajeto de visita. O fato de serem blocos de concreto dificultaria a depredação ou furto da mesma, bem como não seria necessário à colocação das mesmas antes do início do circuito ou retirá-las ao final das visitas, dessa maneira seria poupado tempo e dinheiro.

O fundo da placa seria branco com as letras em preto para uma boa visualização, cada letra teria $2 \mathrm{~cm}$, no estilo Arial Black, e os blocos de concreto com $50 \mathrm{~cm}$ de altura, $70 \mathrm{~cm}$ de largura e $70 \mathrm{~cm}$ de comprimento (Figura 4).
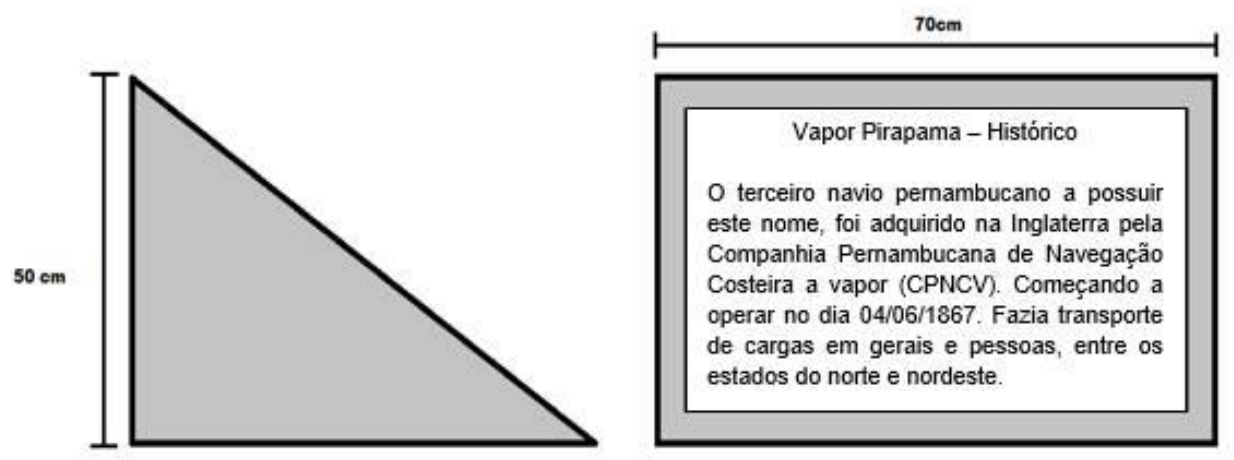

Figura 4: Modelos de base e placa, respectivamente. Fonte: Ezequiel Sena, 2017.

\section{Exigências}

Para mergulhar no Vapor Pirapama, o público-alvo precisa ter a idade mínima estabelecida para - Open Water Diver (mergulho básico), qual seja, 12 anos. Sendo este o pré-requisito que 
habilita a realização do mergulho autônomo até $25 \mathrm{~m}$ de profundidade (variando a profundidade e a idade de acordo com a certificadora de mergulho).

Já embarcados e antes do mergulho, todos receberão informações complementares das aulas já ministradas na parte teórica, além de dados sobre o bioma local do naufrágio, dados sobre segurança pessoal e coletiva, preservação do meio ambiente e comportamento a bordo durante o trajeto da embarcação. Para que as recomendações se tornem mais assimiláveis, parte dessas informações será sob a forma de vídeos.

\section{Circuito Arqueoturístico}

Após a embarcação pairar sob máquinas, um mergulhador descerá, até o naufrágio onde talingará o cabo guia com a boia da embarcação até o ponto de amarração na poita do naufrágio, bem como irá conferir o dispositivo do circuito. Em seguida, o instrutor acompanhará os mergulhadores em uma visita guiada, com tempo hábil para que cada um possa ler cada placa e seguir, como em um museu, uma trajetória determinada.

O trajeto feito com as placas abordará: o histórico do vapor, especificações do navio, os estados que faziam parte do trajeto da embarcação durante seu período de funcionamento, o fator causador do naufrágio e por fim, os artefatos do navio como as caldeiras, rodas e leme (Figura 5).

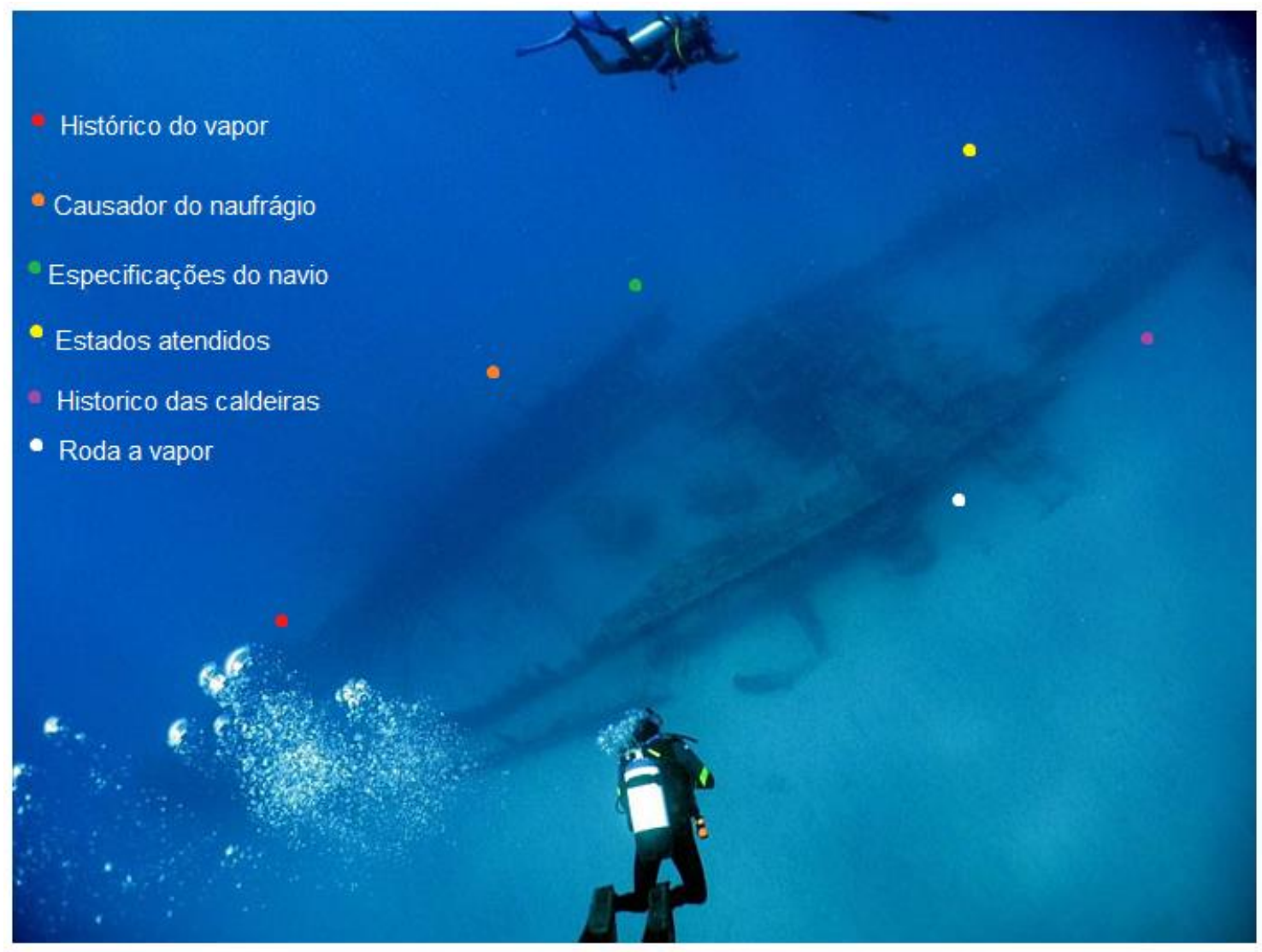

Figura 5: Trajeto sugerido. Fonte: Dolphin Eye, 2016. 
Na volta à superfície, o instrutor responderá aos possíveis questionamentos dos mergulhadores. No segundo mergulho os visitantes estão liberados para fotografias e filmagens.

\subsection{Informações das placas}

Para conceituação, dados históricos e náuticos dos aparelhos e acessórios ainda existentes no navio, foram utilizadas como orientação as contidas nas publicações de Fonseca (2005) e Cherques (1999). As 10 placas a serem fixadas no leito marinho conterão os seguintes dados:

Histórico do vapor - Pirapama ("onde o peixe salta" na língua Tupi) foi o terceiro navio pernambucano a possuir este nome, adquirido na Inglaterra, em 1867, pela Companhia Pernambucana de Navegação Costeira a Vapor (CPNCV). Fazia o transporte de pessoas e cargas em geral.

Fator causador do naufrágio - Serviu de pontão por, pelo menos, 10 anos, antes de seu casco apresentar infiltração pela água, sendo então descartado e afundado a 6 milhas náuticas do Recife, provavelmente, depois de 1908, portanto o fator foi humano com um viés proposital.

Especificações do navio - Possui 60 metros de comprimento, $10 \mathrm{~m}$ de boca e 2,64 $\mathrm{m}$ de calado, deslocando 312 toneladas, suas máquinas possuíam 120 cavalos-vapor e tinha uma tripulação de 34 homens.

Histórico das caldeiras - A meia nau, ou seja, no centro da embarcação encontra-se o local das caldeiras, a engenhosa estrutura de propulsão que remete ao passado, a máquina rotativa de ação dupla, na qual o vapor era introduzido de ambos os lados do pistão, de modo a produzir um movimento para cima e para baixo.

Roda a vapor - Caídas a meia nau, ao lado das máquinas, estão os eixos e os restos das rodas de pás, movidas pelas caldeiras que faz funcionar pelo vapor uma ou mais rodas de pás, também chamadas de roda de água, que funcionam como mecanismos de propulsão.

Maquinário a vapor - A máquina é do tipo Oscillating engines, que impulsionavam um par de rodas de pás, que foram retiradas antes do afundamento.

Leme - Aparelho destinado ao governo de uma embarcação mede 2,6 m.

Âncora - Peça do equipamento que, lançada ao fundo do mar, faz presa nele e aguenta o navio a que se acha ligada por meio da amarra. Existem 18 tipos de âncoras, a do navio é do tipo almirantado.

Escovém - Cada um dos tubos ou mangas de ferro por onde gurnem as amarras do navio, do convés para o costado. Existe um, na altura da bochecha, para cada bordo do navio.

Estados da rota comercial - O vapor fazia, normalmente, o comércio marítimo entre os estados do Norte/Nordeste, esporadicamente ia aos estados do Sul/ Sudeste e ao Arquipélago de Fernando de Noronha.

Abaixo um croqui do estado do Pirapama em 2011 (Figura 6). 


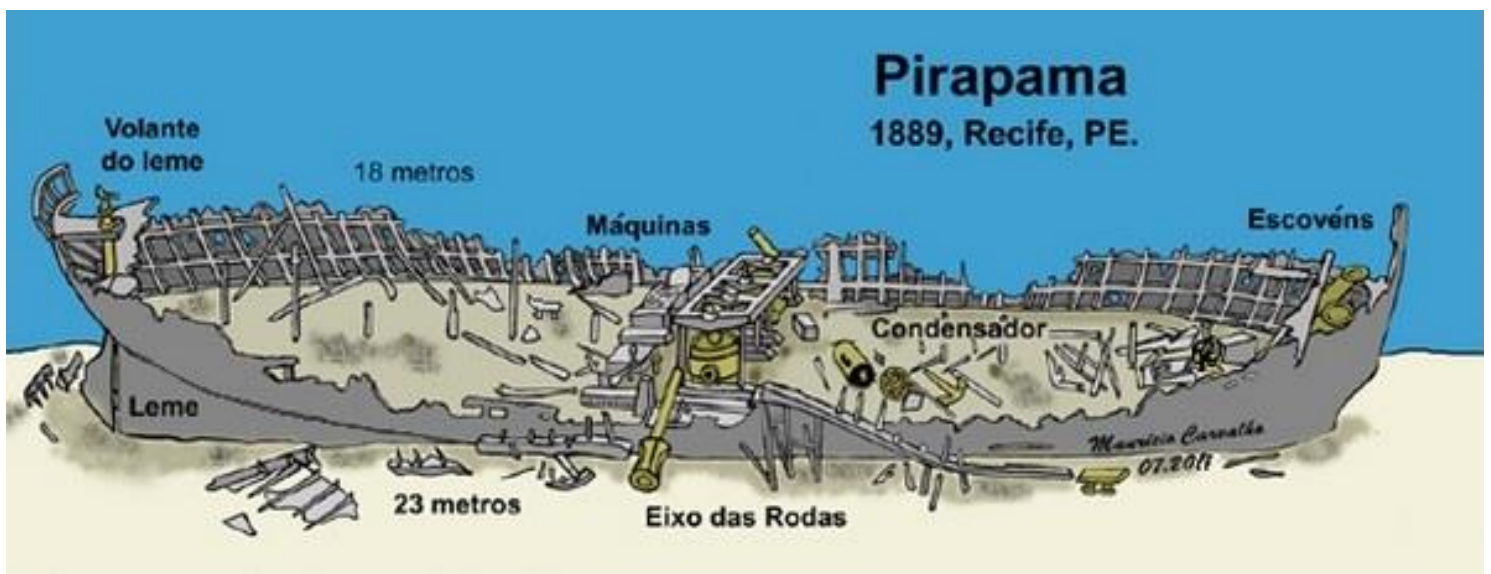

Figura 6: Croqui do Vapor Pirapama. Fonte: Maurício Carvalho, 2011.

\section{Entorno da Embarcação}

O que torna o naufrágio do Vapor Pirapama um dos mais visitados da costa pernambucana devese, em grande parte, ao seu estado de preservação, histórico popular e importância para as pesquisas sobre fauna e flora marítima. Estas características transformam o seu entorno, em um grande catalisador turístico para os mergulhadores dos mais variados interesses.

As águas quentes da capital de Pernambuco tornam o mergulho no naufrágio agradável, e ainda podem contar com uma ótima visibilidade durante o verão, entre os últimos e primeiros meses do ano, sendo possível perceber a biodiversidade existente no navio, que se incorporou bem ao meio marinho tornando-se um verdadeiro habitat natural para diversas espécies da flora e fauna marinha.

De acordo com alguns pesquisadores, "naufrágios são classificados como ambientes artificiais, estruturas imersas em ecossistemas aquáticos (principalmente marinhos) que fornecem abrigo, substratos consolidados, áreas de crescimento, alimentação e de berçário" Lira et al. (2010: 155).

Em local privilegiado, o Pirapama se transformou em um grande atrativo para as várias espécies de peixes, moluscos e esponjas, onde:

entre 2001 e 2007 mergulhos autônomos foram realizados para coletar, observar e fotografar as espécies. Um total de 76 táxons foi registrado para a fauna séssil e sedentária, pertencentes aos seguintes filos: Porífera (Demospongiae e Calcarea), Cnidária (Hydrozoa e Anthozoa), Mollusca (Bivalvia e Gastropoda), Annelida (Polychaeta), Arthropoda (Cirripedia), Bryozoa (Gymnolaemata), Echinodermata (Asteroidea e Echinoidea), e Chordata (Ascidiacea). A maior quantidade de espécies foi de Porifera e Bryozoa, com 13 espécies listadas para cada um. Onze novas ocorrências foram registradas para o Estado de Pernambuco, o hidróide Halopteris polymorpha e dez espécies de briozoários, uma deles sendo o primeiro registro para o Brasil (Scrupocellaria curacaoensis). A biodiversidade do 
Pirapama foi considerada típica quando comparada com a de outros naufrágios que foram estudados no mundo (Lira et al., 2010: 155).

A superfície lateral da embarcação está coberta por esponjas, na parte interna tem-se um verdadeiro recife de coral artificial, no qual o estudo realizado por Lira et al. demonstra um exemplo de que toda essa riqueza biológica contribui para a preservação e atração turística do naufrágio, agregando mais valor científico ao naufrágio (Figura 7).

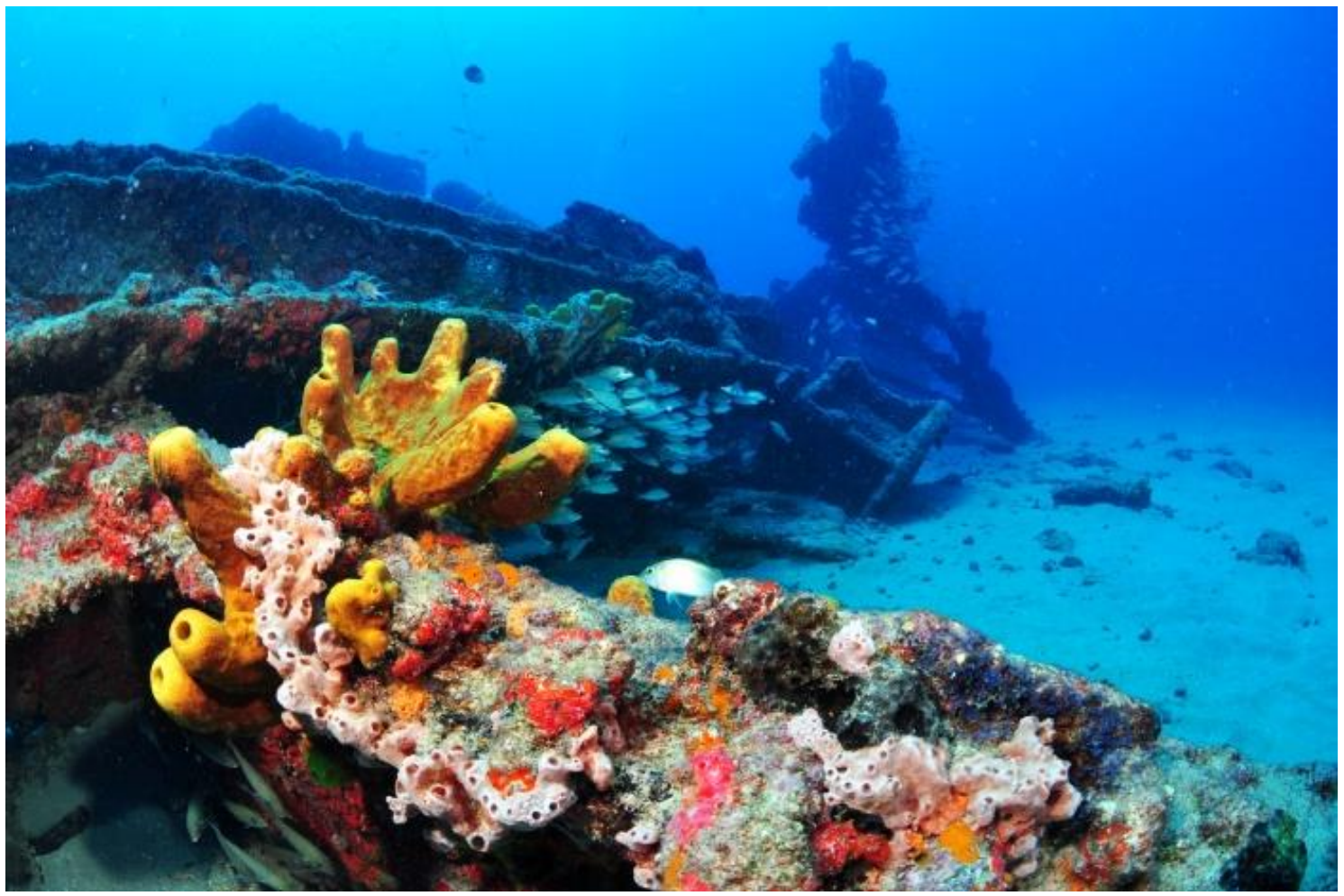

Figura 7: Biodiversidade no naufrágio do Vapor Pirapama. Fonte: Dolphin Eye, 2016.

\section{Conclusões}

O Pirapama foi escolhido por sua importância histórica e por ser "o mais visitado de todos os naufrágios da costa pernambucana" (Brasil Mergulho, 2017). Com a criação de um circuito arqueoturístico ao naufrágio do vapor, pretende-se musealizar esse grande artefato em mar aberto, incorporando-o ao patrimônio cultural subaquático da cidade, além de proporcionar o desenvolvimento econômico local com esse mercado específico, oferecendo um produto turístico sem ignorar a preservação dos sítios de naufrágios.

Como ainda não existe uma política pública governamental para a gestão do patrimônio arqueológico subaquático cabe, portanto, aos profissionais das Ciências Humanas (arqueólogos, antropólogos, historiadores, geógrafos e museólogos), exercer sua função social, tornando acessível o conhecimento sobre o patrimônio cultural submerso da cidade do Recife e participando ativamente em todas as etapas de elaboração do circuito arqueoturístico. 
O intuito é que os frequentadores destes ambientes subaquáticos não apenas apreciem a exuberante fauna e flora marinha com as quais são contemplados os naufrágios, mas que também atentem para o resgate histórico do local e ao não manuseio de materiais arqueológicos, incutindo noções de preservação patrimonial independente do local onde estejam acondicionados esses objetos.

Deixa-se aqui o desejo de que a ideia seja recebida com entusiasmo e que traga novos adeptos à causa, além de contribuições na metodologia sugerida e na produção de mais conhecimento para as diversas áreas que dialogam sempre, fortalecendo o caráter interdisciplinar da ciência.

\section{Referências}

BARBOSA, M. S. Desvendando o Naufrágio Do Vapor Bahia, PE, Brasil (1887): o olhar da Arqueologia Subaquática. Dissertação (Mestrado em Arqueologia). Centro de Filosofia e Ciências Humanas, Universidade Federal de Pernambuco. Recife, 2014.

BRASIL MERGULHO. Pirapama. Web. Disponível em: < https://www.brasilmergulho.com/pirapama/>. Acesso em: 30 jun. 2017.

CARVALHO, M. Naufrágio Pirapama. Web. Disponível em: <http://www.naufragiosdobrasil. com.br/naufpirapama.htm>. Acesso em: 15 ago. 2014.

CARVAlHO, M.. Em Recife Pirapama. Revista Sub, n. 15, maio 1996. Disponível em: <http://www. naufragiosdobrasil.com.br/matpirapama3.htm>. Acesso em: 15 ago. 2014.

CARVALHO, M.; RIOS, C. Pirapama: novas descobertas põem fim a distorções sobre naufrágio. Revista Mergulho, ano 15, n. 184, nov. 2011. Disponível em: <http://www.naufragiosdobrasil. com.br/matedestinonaufragiopirapama.htm>. Acesso em: 15 ago. 2014.

GOULART, L. B. G. J. Processos de Formação Arqueológicos de Sítios de

Naufrágios: uma proposta sistemática de estudos. Dissertação (Mestrado em Arqueologia). Universidade Federal de Sergipe. Laranjeiras, 2014.

LIRA, S. M. A.; FARRAPEIRA, C.M.R.; AMARAL, F.M.D.; RAMOS, C.A.C. Sessile and sedentary macrofauna from the Pirapama Shipwreck, Pernambuco, Brazil. Biota Neotrop, v. 10, n. 4, 2010. Disponível em: <http://www.scielo.br/pdf/bn/v10n4/21.pdf>. Acesso em: 22 ago. 2014.

PROPRIEDADES e vantagens das chapas acrílicas. Instituto Nacional para o Desenvolvimento do Acrílico. Web. Disponivel em: <http://www.indac.org.br/propriedades-e-vantagens-das-chapas-acrilicas.php>. Acesso em: 22 ago. 2014.

RECIFE, a calçada do mar. Jornal O Hoje. Disponível em: <http://www.portalohoje.com.br /homologacao_20052013/essencia/recife-a-calcada-do-mar/>. Acesso em: 22 ago. 2014. 
FERREIRA, I. C.; SILVA, J. J.dos S.; NASCIMENTO, E.S. do; RIOS,C.

RIOS, C. Arqueologia Subaquática: identificação das causas de naufrágios nos séculos XIX e XX na costa de Pernambuco. Tese (Doutorado em Arqueologia). Centro de Filosofia e Ciências Humanas, Universidade Federal de Pernambuco, Recife, 2010. 